\title{
OS EFEITOS DA COVID-19 NO TURISMO DA CIDADE DO RIO DE JANEIRO: OPORTUNIDADES E DESAFIOS
}

\author{
Deborah Moraes Zouain \\ Doutora em Engenharia de Produção pela Universidade Federal do Rio de Janeiro - UFRJ \\ Professora do Programa de Pós-Graduação em Administração da Universidade do Grande Rio - Unigranrio \\ Coordenadora do Núcleo de Pesquisa em Turismo da Unigranrio \\ deborahzouain@gmail.com \\ Paola Bastos Lohmann \\ Doutora em Turismo pela Universidade de Aveiro - Portugal \\ Universidade de Aveiro - Portugal \\ Pesquisadora do Núcleo de Pesquisa em Turismo da Unigranrio \\ paolalohmann@gmail.com
}

\begin{abstract}
Gabriela De Laurentis Mestranda no Programa PPDESDI - Pós-Graduação em Design da ESDI/Escola de Desenho Industrial Universidade Estadual do Rio de Janeiro - UERJ Pesquisadora do Núcleo de Pesquisa em Turismo da Unigranrio gabydelaurentis@yahoo.com

Kaarina Barbosa Virkki Mestranda no Programa EICOS - Pós-Graduação em Psicossociologia de Comunidade e Ecologia Social Universidade Federal do Rio de Janeiro UFR. Pesquisadora do Núcleo de Pesquisa em Turismo da Unigranrio kaarina.virkki@gmail.com

Flora Thamiris Rodrigues Bittencourt Doutoranda em Administração Universidade do Grande Rio - Unigranrio Pesquisadora do Núcleo de Pesquisa em Turismo da Unigranrio flora_thamiris@hotmail.com
\end{abstract}

\section{Resumo}

Objetivo do estudo: Analisar os efeitos da pandemia da Covid-19 no turismo do Rio de Janeiro e entender as oportunidades e os desafios no destino.

Metodologia/abordagem: Pesquisa quantitativa de caráter exploratório, com aplicação de questionário on-line com 338 respondentes da cidade do Rio de Janeiro, de 05 de junho a 25 de agosto de 2020. Para tanto, foi realizada uma análise descritiva de dados e teste de hipótese para comparar as percepções dos respondentes antes e durante a pandemia.

Originalidade/Relevância: Investigação dos efeitos da pandemia no turismo, com estudo empírico na cidade do Rio de Janeiro, que se configura como um importante destino turístico, tanto do receptivo, como do emissivo doméstico e internacional.

Principais resultados: A pandemia gerou menor propensão a deslocamentos nacionais e, em especial, internacionais, além de oportunidade para o carioca conhecer mais a sua cidade e Estado, sendo pertinente o aumento da oferta de produtos e serviços turísticos para residentes. A maior preocupação dos cariocas é em relação à qualidade de vida e à saúde, assim como ao distanciamento social. Ademais, há a necessidade de elaboração e implementação de protocolos de segurança e comunicação das condições sanitárias dos destinos e dos atrativos turísticos; questões essas a serem levadas em conta ao longo das jornadas de viagens.

Contribuições teóricas/metodológicas: Cobrir uma lacuna empírica com dados sobre os efeitos da pandemia no turismo da cidade Rio de Janeiro e contribuir para a produção científica ainda incipiente sobre o tema.

Palavras-chave: Turismo. Pandemia. Residentes. Covid-19. Rio de Janeiro.

\section{Cite como}

American Psychological Association (APA)

Zouain, D. M., Lohmann, P. B., Laurentis, G., Virkki, K. B., \& Bittencourt, F. T. R. (2022, jan./abr.). Os efeitos da Covid-19 no turismo da cidade do Rio de Janeiro: oportunidades e desafios. PODIUM Sport, Leisure and Tourism Review, São Paulo, 11(1), 59-88. https://doi.org/10.5585/podium.v11i1.19517. 


\title{
THE EFFECTS OF COVID-19 ON RIO DE JANEIRO CITY'S TOURISM: OPPORTUNITIES AND CHALLENGES
}

\begin{abstract}
Objective of the study: To analyze the effects of the Covid-19 pandemic on the tourism in Rio de Janeiro and to understand the opportunities and challenges in the destination.

Methodology/approach: Quantitative exploratory research, with application of an online survey with 338 respondents from the city of Rio de Janeiro, from June 5th to August 25th, 2020. For this purpose, a descriptive data analysis and a hypothesis test were performed to compare the perceptions of respondents before and during the pandemic.

Originality/Relevance: Investigation of the effects of the pandemic on tourism, with an empirical study in the city of Rio de Janeiro, which is configured as an important tourist destination, both in terms of incoming and outgoing domestic and international tourism.

Main results: Less propensity to national and, especially, international travel, due to the pandemic situation and an opportunity for the cariocas to get to know their city and state, being opportune to increase the offer of touristic products and services for residents. Cariocas are more concerned about quality of life and health, as well as social distance. There is a need to develop and implement safety protocols and communication of sanitary conditions of destinations and tourist attractions; these issues should be considered along the travel journeys.

Theoretical/methodological contributions: To cover an empirical gap on data about the pandemic effects on tourism in the city of Rio de Janeiro and to contribute to the incipient scientific production on the subject
\end{abstract}

Keywords: Tourism. Pandemic. Residents. Covid-19. Rio de Janeiro.

\section{LOS EFECTOS DEL COVID-19 EN EL TURISMO DE LA CIUDAD DE RÍO DE JANEIRO: OPORTUNIDADES Y DESAFÍOS}

\section{Resumen}

Objetivo del estudio: Analizar los efectos de la pandemia Covid-19 sobre el turismo en Río de Janeiro y comprender las oportunidades y desafíos en el destino.

Metodología/abordaje: Investigación exploratoria cuantitativa, con aplicación de un cuestionario en línea con 338 encuestados en la ciudad de Río de Janeiro, del 5 de junio al 25 de agosto de 2020. Para eso, se realizó un análisis descriptivo de datos y una prueba de hipótesis para comparar las Percepciones de los encuestados antes y durante la pandemia.

Originalidad/Relevancia: Investigación de los efectos relacionados con la Pandemia en el turismo, teniendo como estudio empírico a Río de Janeiro, que se configura como un importante destino turístico, tanto en términos de receptividad como de egreso, nacional e internacional.

Principales resultados: Menor propensión a los viajes nacionales y, en especial, internacionales, en este momento de pandemia y mayor interés de los cariocas en conocer más sobre su propia ciudad y alrededores, siendo oportuno el incremento en la oferta de productos y servicios turísticos al público local. Mayor preocupación de los cariocas por la calidad de vida y salud, así como por la distancia social, los protocolos de seguridad y las condiciones sanitarias de los destinos y atractivos turísticos; estas cuestiones deben tenerse en cuenta a lo largo de los viajes.

Aportes teórico/metodológicos: Cubrir un vacío empírico con datos sobre los efectos de la Pandemia en el turismo en la ciudad de Río de Janeiro y contribuir a la producción científica aún incipiente sobre el tema.

Palabras clave: Turismo. Pandemia. Residentes. Covid-19. Rio de Janeiro. 


\section{Introdução}

A rápida disseminação do coronavírus no mundo gerou danos consideráveis à economia global e o turismo está certamente entre as indústrias mais afetadas (Tsai, 2021). Neste sentido, a preocupação de autoridades nacionais e internacionais quanto aos resultados da Pandemia da Covid-19 para a sociedade torna essa temática prioritária nas pautas das diferentes instâncias de governos nacional e internacional.

Deve-se mencionar, especialmente, o turismo internacional, que tem sido um dos setores mais impactados negativamente sob o contingente de 'bloqueios' nas respostas dos governos à crise sanitária (Cooke \& Nunes, 2020). Para os autores Valencio e De Oliveira (2020, p.97), "tudo parece convergir em um cenário de recessão no aspecto de que os estados atuais estão longe de enfrentar com equilíbrio os grandes desafios epistemológicos e ambientais que estão por vir".

Durante os primeiros dias da quarentena, a qual foi instituída por diversos países como forma de conter o contágio pelo coronavírus, voos nacionais e internacionais foram cancelados, além de hotéis econômicos e de luxo fecharem as portas temporariamente e alguns até definitivamente (Coelho, 2020). Feiras e eventos tradicionais presenciais foram cancelados ou adiados, como o $27^{\circ}$ Congresso Mundial de Arquitetura, por exemplo, no qual a cidade do Rio de Janeiro foi designada como a capital mundial da Arquitetura pela UNESCO (Abdala, 2020). No Japão, os Jogos Olímpicos Tóquio 2020 foram adiados para os meses de julho e agosto de 2021, mas sem a entrada de turistas estrangeiros devido à situação emergencial (G1, 2021). Além disso, ainda por cima contou com alta rejeição da população local contra a realização do megaevento (BBC News, 2021).

No caso do Rio de Janeiro, não só o Estado, mas também a capital sentiu os efeitos socioeconômicos da Pandemia, juntamente com os municípios nos arredores e cidades de outros Estados da Federação. À proporção que a pandemia da Covid-19 se disseminou no Brasil trouxe números significativos sobre o avanço do vírus no país. Segundo dados do Johns Hopkins University Center, no mês de novembro de 2020 o Brasil ocupava a terceira posição em números cumulativos de infectados, com 5.781.582 de casos desde o início da Pandemia, ficando atrás somente dos Estados Unidos e da Índia (Johns Hopkins University Medicine, 2020).

A crise instalada no país por conta da pandemia afetou negativamente "investimentos em capital fixo, o comércio internacional, os restaurantes, os setores de hotelaria, turismo, 
eventos e entretenimento, etc" (Bartholomeu, Tunes, \& Lencioni, 2020, p. 18). Além disso, o turismo global exige um pensamento político inovador diferente do que foi testado até aqui, dado que não conseguiu inovar, o que resultou em efeitos negativos para o planeta (Cooke \& Nunes, 2020).

E, neste sentido, torna-se ainda importante considerar que esta crise parece ter reforçado tendências pré-existentes que podem ter efeitos mais imediatos do que o previsto na economia, tais como mudanças dos hábitos de consumo de "turistas e viajantes" e no "comércio eletrônico" (Kraenzlin, Meyer, \& Nellen, 2020). Novas dinâmicas têm surgido na forma de se consumir produtos e serviços, em função da limitação do tráfego de pessoas e das restrições do comércio físico ao longo da pandemia, gerando novos hábitos nos consumidores e aumentando de forma significativa o comércio eletrônico e a interação por meio digital.

Nesse cenário, há ainda que se considerar a saúde do viajante, uma vez que o turismo é uma área que trata de riscos tanto individuais quanto coletivos, ocasionados pela movimentação de pessoas e por sua interação com diversos ambientes. É por esse e outros motivos que estudos de saúde daqueles que viajam e dos que residem em destinos turísticos são tão importantes para o país, em especial neste momento. Findlater e Bogoch (2018) ressaltam que o próprio turista pode ser visto como um importante ator na disseminação dos vírus em epidemias no mundo. Ademais, atualmente, torna-se imprescindível adotar e desenvolver medidas para maior prevenção e monitoramento da pandemia, não apenas durante o ápice, mas também após a fase de controle.

Tendo em vista a necessidade de estudos e discussões que enriqueçam e aprofundem a abordagem desta temática emergente, o presente artigo tem como principal objetivo analisar os efeitos da pandemia da Covid-19 no turismo do Rio de Janeiro. Dentre os objetivos secundários, destacam-se: identificar os novos hábitos de viagens, propensão à realização de viagens domésticas e internacionais, preocupação com protocolos sanitários e nível de interação com o ambiente digital e com o turismo local, além de pontuar desafios e oportunidades para o turismo neste novo contexto.

O percurso metodológico envolveu pesquisa bibliográfica a respeito do estado da arte da temática, ainda incipiente, sobre impactos da Pandemia da Covid-19 no turismo, bem como referências sobre a relação dos residentes com o turismo, inovações no segmento em suas diferentes esferas e saúde do viajante. Após essa etapa foi feita coleta de dados primários por meio de pesquisa quantitativa de caráter exploratório do tipo survey com aplicação de questionário online. $\mathrm{O}$ estudo faz parte de uma pesquisa mais abrangente entre Brasil e Portugal, 
que contou com 1506 respondentes, e os resultados aqui apresentados contemplam um recorte com 338 respondentes, que residem na cidade do Rio de Janeiro.

\section{Turismo no cenário de incertezas da Pandemia da Covid-19}

Devido à pandemia da Covid-19, o turismo mundial foi gravemente afetado. Segundo divulgado pela Organização Mundial da Saúde (OMS), a China foi o primeiro país a enfrentar o coronavírus. Reconhecida pela Organização Mundial do Turismo (OMT) como líder no turismo global, tanto como mercado-fonte quanto como destino líder (Ayittey et al., 2020), foi o país que sofreu primeiro as consequências na sua atividade turística. Em seguida, diversos países no restante do mundo sentiram esses efeitos de forma gradativa.

Segundo Gössling, Scott e Hall (2020) as restrições de viagens internacionais, regionais e locais afetaram as economias nacionais, incluindo os sistemas de turismo, ou seja, viagens internacionais, turismo doméstico, visitas diárias e segmentos diversos como transporte aéreo, cruzeiros, transporte público, alojamento, cafés e restaurantes, convenções, festivais, reuniões ou eventos esportivos. Neste sentido, a crise sistêmica do turismo foi incrementada pelo bloqueio de estruturas temporárias que permitem movimento e acomodação de milhões de pessoas, denominadas de turistas pela Organização Mundial do Turismo (OMT) (Mantecón, 2020).

As áreas da economia estão sendo impactadas de formas diferentes, como mostra o relatório da ALG Transport \& Infrastructure (2020), baseado em estudos da Moody's Investor Service, em que a exposição a impactos negativos é altamente dependente do setor. Linhas aéreas, varejo, turismo e alguns tipos de produção industrial estão entre os segmentos mais afetados, nos quais ações de mitigação de riscos são críticas.

Segundo o relatório, as áreas de transporte/logística de entrega, comida e telecomunicação são ramos com menor exposição de impacto negativo e que apontam expansão dos seus negócios. Exemplos de setores com potenciais impactos positivos são também as companhias de serviço de internet, varejo online e mineração de ouro. Em tempos de flutuação cambial devido a crises mundiais, muitos investem em ouro (devido à sua baixa flutuação cambial) ao invés de fazer aplicações em outras moedas. Na Figura 1 é possível apreender alguns dos setores mais impactados, de acordo com a ALG Transport \& Infrastructure (2020). 


\section{Figura 1.}

Impacto Econômico da Covid-19

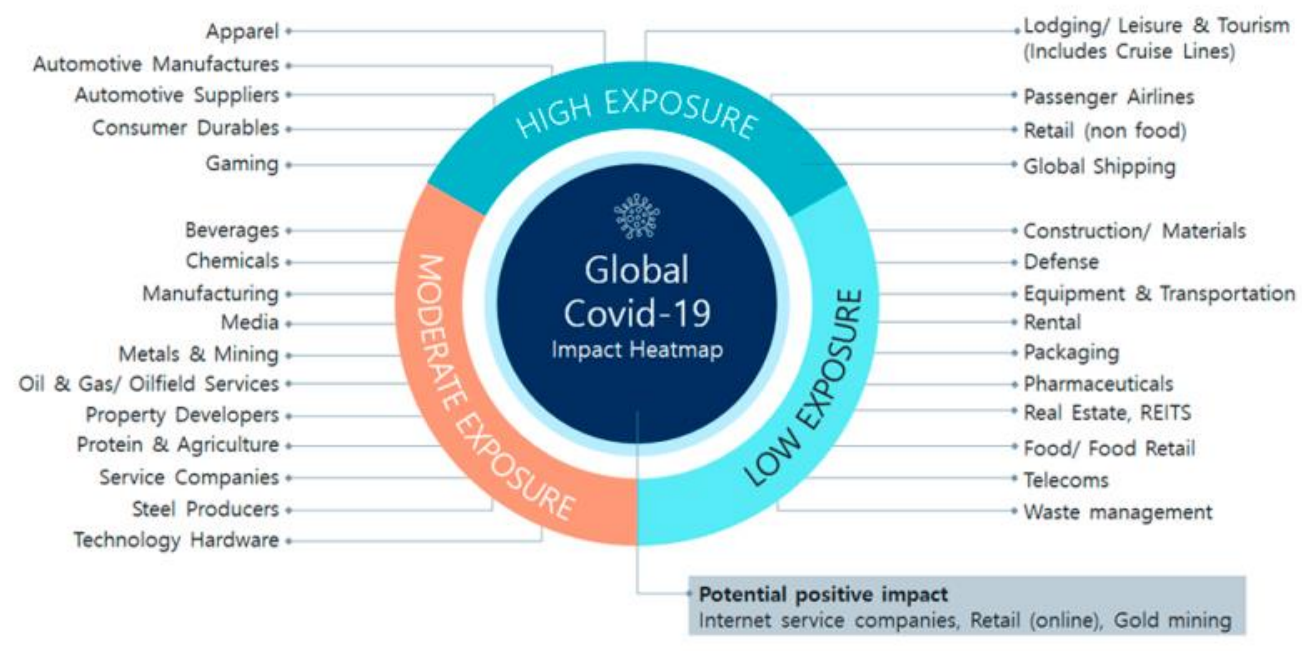

Fonte: ALG Transport \& Infrastructure (2020).

Segundo o autor Martín (2020), a complexidade da crise do ponto de vista do turismo exige um esforço de esclarecimento sobre suas principais dimensões e elementos moduladores que marcarão a evolução do turismo nos próximos meses e, talvez, anos. Essas quatro dimensões da crise que se inter-relacionam são: a dimensão da saúde, a alteração dos padrões de mobilidade, a dimensão econômica e a mudança no comportamento dos turistas. Conforme aponta o autor, paralelamente os elementos que estão modulando os impactos da crise são: a intervenção pública, o comportamento das empresas e, por último, a resiliência da sociedade. Por sua vez, essas quatro dimensões afetam simultânea e assimetricamente os mercados de origem e de destino.

A crise possibilitou abrir uma etapa de transformação individual e coletiva do setor turístico, cujo alcance dependerá da gravidade das quatro dimensões acima mencionadas. Em qualquer cenário futuro do setor turístico será necessário potencializar as reais condições e percepções dos clientes quanto à segurança entendida em um sentido amplo (pessoal, alimentação, saúde etc.). O setor empresarial, por exemplo, nos países de origem, passará a desempenhar um papel central por meio das operadoras de turismo, agências de viagens virtuais e companhias aéreas (Martín, 2020). 
Além disso, o turismo de negócios nos destinos enfrentará um cenário incerto e mutante e terá que valorizar a profissionalização das organizações, dos operadores e da dinâmica do mercado. O setor do turismo deverá reforçar a sua orientação para o cliente e as suas novas necessidades por meio da melhoria das experiências turísticas, incluindo maior autenticidade ou atendimento a segmentos emergentes após a crise, como as estadias temporárias de visitantes em teletrabalho do destino (Martín, 2020).

Segundo Jesus, Kamlot e Dubeu (2020) este novo contexto da economia também se caracteriza pelas interações de baixo (ou nenhum) contato. Além disso, medidas de segurança sanitária, uso de ferramentas online, como aplicativos de conferência virtual para interagir e trabalhar, substituição da interação humana por robôs no setor de serviços e a mudança de eventos presenciais por on-line ou híbridos que também apresentam baixo nível de contato. Vale ressaltar que a tecnologia e acessibilidade à internet terão um papel fundamental nas tendências globais de consumo e no turismo (Angus, 2018).

O termo cunhado de low touch economy, traduzido como economia de pouco ou baixo contato, é o que tem se vivenciando ao longo da pandemia da Covid-19 por meio da implementação e incentivo de isolamento social, de modo a evitar multidões e contato físico com outras pessoas. O isolamento social nos direciona a:

(...) consumir de formas diversas da que estávamos acostumados, passando a usar recursos da tecnologia da informação para suprir o contato direto com o vendedor. Se você comprou comida por aplicativo, fez reuniões de trabalho em seu home office, conversou com seu médico à distância e seu personal aplicou o treino pela telinha do seu Smartphone, você se inseriu na Low Touch Economy. (Comunidade Sebrae, 2020).

Com isso, observa-se uma mudança de hábitos em diversas áreas de conhecimento e isso não é diferente no turismo. Uma das tendências e soluções para a atividade turística nesse momento é a crescente procura por destinos mais remotos, longe de aglomerações e com maior contato com a natureza e atividades ao ar livre, de forma a evitar lugares fechados. $\mathrm{O}$ turismo na cidade, arredores e nos próprios países são caminhos e saídas para a retomada do turismo, o que se notou com o início da flexibilização, que permitiu aos brasileiros retomarem deslocamentos em distâncias menores ou mesmo na própria cidade (Serviço Brasileiro de Apoio às Micro e Pequenas Empresas [SEBRAE], 2020).

\subsection{O residente e o turismo: mudanças no contexto da pandemia da Covid-19}

Segundo Everingham e Chassagne (2020) a crise da pandemia da Covid-19 exigiu que se reduzisse imediatamente a maneira como se viaja e se vive, de modo a conectar-se mais 
localmente, fazer compras localmente e limitar o consumo ao que realmente é necessário. As autoras salientam que "por meio da crise, vem a criatividade e os desafios ao "individualismo atomizado" que sustenta o consumo de viagens" (Everingham \& Chassagne, 2020, p. 560).

Transpondo este debate para a reflexão sobre o protagonismo dos residentes no desenvolvimento de políticas públicas de turismo, Lehto, Davari e Park (2020) discutem que a pandemia da Covid-19 pode ser um importante lembrete de que talvez seja a hora de reavaliar o que significa o turismo para os anfitriões de locais turísticos. Os autores argumentam que pode ser interessante para os destinos reorientarem seus indicadores de resultados baseados em satisfação para focar no bem-estar tanto de turistas quanto de anfitriões. Quando o bem-estar é um objetivo prioritário, o convívio surge, aumentando a coesão social. E "isso pode exigir uma mudança filosófica no tratamento de visitantes como "outros" - para torná-los "parte de nós", parte do tecido social da humanidade" (Lehto et al., 2020, p. 1078).

O protagonismo da comunidade local no desenvolvimento do turismo muitas vezes é ignorado, tendo em vista que as políticas públicas costumam ser voltadas para o atendimento das necessidades de um ator, o turista. Há um equívoco em desconsiderar o residente, pois "quanto maior o envolvimento local e mais desenvolvidas as estratégias de participação social em planejamento e implementação de projetos, mais evidentes tendem a ser os níveis de protagonismo social e a sustentabilidade das iniciativas em curso" (Irving, 2009, p.114).

Rabinovici e Irving (2015) consideram que são raras as experiências inovadoras e interessantes de participação social no turismo, havendo uma face excludente nas iniciativas do setor que dificulta a difusão do turismo como um meio de inclusão social. Uma grande aliança com a sociedade seria altamente benéfica por vários motivos, conforme Sánchez (2020), visto que a recuperação do turismo diz respeito a todos, não apenas a órgãos públicos e empresas.

$\mathrm{Na}$ busca por identificar novas micro geografias do turismo, surge um termo recentemente cunhado de 'turista-cidadão', para o qual são oferecidas inúmeras oportunidades de conhecer com um outro olhar: as ruas, monumentos, arquitetura, personagens, segredos e curiosidades que fazem parte da narrativa da cidade, muitas vezes invisíveis no dia a dia. Segundo Gastal (2006), há uma mudança no conceito de turismo, pautado pelas distâncias espaciais, para uma atividade que prioriza o aproveitamento do tempo e do espaço de uma forma diferente da rotina. Ou seja, para que o conceito de turista-cidadão seja posto em prática "não seria mais necessário sair dos limites da cidade, pois se tornou o território da multiplicidade, permitindo sermos turistas mesmo sem abandonar seu território" (Gastal, 2006, p. 8) 
Segundo Gastal e Moesch (2007), no conceito do "turista-cidadão" o habitante desenvolve uma relação diferenciada com o local onde mora e vivência práticas não rotineiras dentro da sua própria cidade. Seria uma forma de descobrir o território cotidiano sob uma nova ótica, na qual o habitante aproveita os espaços culturais, históricos, de lazer e comerciais com uma percepção diferente do seu cotidiano.

Ademais, colocar o residente na posição de usuário da cidade, permitindo que ele descubra e explore a cidade sem o distanciamento comum que o "fazer turismo" causa, pode provocar uma percepção diferenciada e uma relação mais próxima entre o cidadão e o turismo. Ao incentivar que moradores assumam a posição de fluxos, para além de suas práticas rotineiras, se apropriando e conhecendo os fixos das cidades com um outro olhar, permite-se que este residente tenha o papel de cidadão turista, de acordo com Gastal (2006). A autora reconhece que o deslocamento dentro da própria cidade dá condições aos moradores a apropriarem-se "com maior competência dos espaços e situações" (Gastal, 2006, p. 9). A possibilidade de conhecimento mais aprofundado da cultura, história e fazeres da cidade estimula o senso de pertencimento e reconhecimento da cidade.

Em um momento em que se faz necessário um desenvolvimento sustentável que considere a importância da cultura, do social e da ética e que envolva métodos participativos para alcance de objetivos, a transformação do residente em turista cidadão pode representar um resgate à cultura local e de valorização da própria identidade (Bartholo, Sansolo, \& Bursztyn, 2009). O sentimento de pertencimento e valorização de um ator que é visto como um passivo do turismo, uma vez que pode promover uma maior cooperação do residente com o desenvolvimento turístico. Maciel e Alves (2015, p. 277) defendem que é "por meio da participação que se alcançará um desenvolvimento mais adequado às realidades locais".

Principalmente no momento atual, a pandemia trouxe a valorização do local não somente para o turismo, como para outros segmentos como produção de alimentos, pequenos comércios e prestação de serviços de negócios próximos às residências, como formas de suporte à economia local (Euromonitor International, 2020).

Quanto ao turismo, o SEBRAE (2020) em seu Boletim de Tendências apontou o conceito de staycation como uma tendência que cresce "a passos largos durante a pandemia" (SEBRAE, 2020). O termo, que tem origem nos Estados Unidos, ganhou força em 2008 durante o período de crise financeira, que impossibilitou muitos americanos de manterem seus hábitos de viagem de longa distância. Com isso, mais cidades começaram a ter como alvo os consumidores locais, anunciando e promovendo o que elas têm a oferecer e tornando as viagens 
de curta distância uma opção mais atraente para estes consumidores (James, Ravichandran, Chuang, \& Bolden, 2017).

A crise global provocada pela pandemia, somada ao temor ou impedimento de realização de viagens longas, parecem incentivar o movimento de ser turista na sua própria cidade ou arredores. Algumas iniciativas que mostram esta busca pelo turismo mesmo em períodos de restrição são: visita a destinos próximos à residência, sem necessariamente incluir o pernoite; day use de hotéis da própria cidade; conhecimento de atrativos turísticos; homeoffice em local diferente de sua residência, com possibilidade de conexão com a natureza; entre outros (SEBRAE, 2020; Castello, 2020; Everingham \& Chassagne, 2020).

O maior interesse em se conhecer a própria cidade e arredores torna oportuno o aumento da oferta de produtos e serviços turísticos para o público local e o fortalecimento de ações que visem fomentar o conceito de turista-cidadão. Para tal, as dinâmicas do território devem ser observadas, entendendo que esses consumidores estão cada vez mais conectados, informados e responsáveis com o meio ambiente, e que em um curto espaço de tempo podem assumir o papel de embaixadores do próprio destino, conhecendo mais o local onde residem e divulgando o que a cidade tem de melhor.

\section{Metodologia}

O presente estudo foi desenvolvido por meio de uma pesquisa quantitativa do tipo $e$ survey de caráter exploratório por meio de coleta de dados primários em formulário online, fazendo uso do formato eletrônico no sistema Survey Monkey. A pesquisa teve como principal objetivo analisar os efeitos da pandemia da Covid-19 no turismo do Rio de Janeiro. Dentre os objetivos secundários, destacam-se: identificar os novos hábitos de viagens, propensão à realização de viagens domésticas e internacionais, a preocupação com protocolos sanitários e nível de interação com o ambiente digital e com o turismo local, além de pontuar desafios e oportunidades para o turismo no contexto da pandemia.

O estudo faz parte de uma pesquisa mais abrangente entre Brasil e Portugal, que contou com 1506 respondentes, e os resultados aqui apresentados fazem parte de um recorte que contempla 338 residentes da cidade do Rio de Janeiro. A coleta de dados compreendeu o período de 05 de junho a 25 de agosto de 2020.

De acordo com a Organização para a Cooperação e Desenvolvimento Econômico [OCDE] (2005), survey é um tipo de pesquisa que tem como objetivo averiguar as características de uma população através de uma coleta de dados de uma amostra da população 
e estabelecer suas características por meio do uso da metodologia estatística. Em relação ao $e$ survey ou Eletronic Survey, Jansen, Corley e Jansen (2007), retratam o mesmo conceito da OCDE, indicando o meio de obtenção dos dados.

Uma pesquisa online é um questionário que os respondentes podem se auto aplicar, utilizando a internet. Esse tipo de pesquisa é criado com formulários na web que contêm um banco de dados para armazenar as respostas e um software de estatística para realizar análises. Há diversos incentivos que são feitos para que as pessoas realizem esses inquéritos online, e um deles é ser inscrito para ganhar um prêmio (Jansen, Corley, \& Jansen, 2007). Entretanto, em pesquisas acadêmicas evitam-se prêmios e prioriza-se a conscientização no preenchimento pela colaboração em emitir sua opinião em um devido assunto e ajudar a construir conhecimento científico.

A evolução da internet fez com que as formas tradicionais de coletas de dados migrassem para meios de coletas alternativas para obtenção de dados primários. Couper (2005), indica que o desenvolvimento e ascensão de novas tecnologias expôs ao mundo da pesquisa novos meios de coleta de dados, como a entrevista de autopreenchimento por computador ou celular, entrevistas via web e sistemas automatizados de entrevista telefônica.

As novas tecnologias possibilitam ganhos para o desenvolvimento do conhecimento. Com a evolução da tecnologia, cada vez mais há necessidade de informações mais rápidas e, com isso, novos métodos para coleta e tratamento de dados pela internet se tornam essenciais e exigem que as técnicas tradicionais combinadas com as novas ferramentas proporcionem dinamismo, eficiência e confiabilidade.

Em relação à amostragem, Watt (1997) faz uma ressalva quanto à auto seleção dos entrevistados, cujo contexto é qualquer pessoa que tiver acesso à internet poder responder ao questionário. Para o autor, quando ocorre esse tipo de seleção amostral, a taxa de conclusão é baixa em comparação aos métodos tradicionais.

Pensando no dimensionamento da amostra, a quantidade de entrevistados foi calculada de forma a se enquadrar nos critérios de significância estatística, levando em conta estimadores que maximizariam a variância da população alvo. Todavia, além do tamanho da amostra, a técnica de coleta é essencial para se garantir a representação da população a ser estudada. Para isso, podem ser utilizadas características como distribuição etária, situação socioeconômica ou demográfica disponibilizadas pelos órgãos de estatística oficiais.

Considerando uma amostra aleatória simples, o tamanho da amostra pode ser obtido a partir da seguinte equação (Bolfarine \& Bussab, 2005, pp. 69-70): 


$$
\mathrm{n}=\frac{\mathrm{Z}_{\alpha}^{2} \times \sigma^{2}}{\mathrm{e}^{2}}
$$

Assim, para determinar o tamanho de uma amostra é preciso fixar uma margem de erro aceitável $\left(\mathrm{e}^{2}\right)$, com certo nível de confiança $\left(\mathrm{z}_{\alpha}^{2}\right)$ e algum conhecimento prévio quanto à variabilidade da população $\left(\sigma^{2}\right)$. Fixando as duas primeiras medidas tem-se como erro máximo de $5 \%(\mathrm{e}=0,05)$ ao nível de confiança de $95 \%\left(\mathrm{z}_{\alpha}=1,96\right)$. Como a medida de variabilidade é desconhecida e considerando que a variável de interesse tem características dicotômicas, as quais se deseja maximizar sua variabilidade, temos $\sigma^{2}=0,5^{2}$. Listados ou parâmetros (ou suas estimativas), tem-se:

$$
\mathrm{n}=\frac{1,96^{2} \times 0,5^{2}}{0,05^{2}} \rightarrow \mathrm{n} \cong 384
$$

Dessa forma, buscou-se obter um tamanho de amostra desta ordem. O estudo com 338 dados coletados apresenta um erro amostral de 5,3\%.

$\mathrm{O}$ instrumento de pesquisa, composto por 32 questões, foi estruturado em blocos temáticos. Ao longo deste artigo são analisadas as seguintes variáveis:

- Propensão à realização de viagem a lazer no país e internacionalmente, disponibilidade financeira para viajar, preocupação com a qualidade de vida e com as condições sanitárias do destino para viajar;

- Comparação de percepções em relação aos hábitos de viagens (antes e durante a pandemia de Covid-19);

- Nível de preocupação com distanciamento social, protocolos de segurança sanitária;

- Nível de interesse em conhecer mais o destino onde reside;

- Nível de interação com o ambiente digital, para identificar o quanto o respondente se considera conectado, informado, ativo com compartilhamento de dados em redes sociais, e responsável com o meio ambiente;

- Perfil: tipo de respondente (representante da academia, setor privado, setor público e sociedade civil), tipo de instituição, gênero, faixa etária, local de residência (cidade, estado e país);

A análise de dados foi feita utilizando o software Statistical Package for the Social Science (SPSS) e foram rodadas frequências simples e cruzamentos de dados. Para as análises 
comparativas de antes e depois, foi feito o teste de amostras emparelhadas, conforme apresentado, a seguir, na análise de dados. Dentre as 8 hipóteses definidas para o estudo, destaca-se que no contexto da pandemia, os residentes pesquisados:

H1: Têm maior propensão em conhecer o próprio país;

H2: Têm menor propensão na realização de viagens internacionais;

H3: Têm menor a disponibilidade financeira para viagem;

H4: Têm maior preocupação com qualidade de vida;

H5: Têm maior preocupação com condições sanitárias do local visitado;

H6: Consideram conhecer mais o destino onde habitam;

H7: Se consideram mais conectados, informados e responsáveis com o meio ambiente;

H8: Têm maior preocupação com a lotação dos atrativos turísticos.

\section{Análise e discussão de resultados}

A seguir, serão apresentados os dados do perfil dos respondentes e as análises e discussão dos resultados da pesquisa.

\subsection{Perfil dos respondentes}

Importante ressaltar que todas as respostas analisadas no presente artigo são referentes a residentes na cidade do Rio de Janeiro, Brasil. Os dados foram coletados com quatro diferentes atores. São eles: representantes da sociedade civil(50\%), empresas do setor privado das áreas de turismo e hotelaria ou saúde(25,1\%), instituições de ensino públicas e/ou privadas das áreas de turismo e hotelaria ou saúde $(20,1 \%)$ e organizações de gestão pública e/ou associações das áreas de turismo e hotelaria ou saúde (4,7\%), como representado na Tabela 1, a seguir.

O intuito de dividir o público respondente em áreas de atuação foi possibilitar o entendimento de como a pandemia afetou cada área de atuação e se haveria diferenças de opiniões de acordo com a atividade profissional do respondente. Neste artigo não serão feitos recortes analíticos por tipo de grupo porque a amostra não é suficiente, mas esse tipo de análise comparativa será feita posteriormente no estudo completo. 
Zouain, D. M., Lohmann, P. B., Laurentis, G., Virkki, K. B., \& Bittencourt, F. T. R. (2022, jan./abr.). Os efeitos da Covid-19 no turismo da cidade do Rio de Janeiro: oportunidades e desafios.

Tabela 1.

Principal Atividade Profissional Desenvolvida em Qual tipo de Organização?

\begin{tabular}{|l|c|c|}
\hline \multicolumn{1}{|c|}{ Tipo de atuação } & Frequência & $\begin{array}{c}\text { Percentual Válido } \\
(\mathbf{\%})\end{array}$ \\
\hline $\begin{array}{l}\text { Instituição Acadêmica Pública ou Privada nas áreas de turismo } \\
\text { e hotelaria ou saúde }\end{array}$ & 68 & 20,1 \\
\hline $\begin{array}{l}\text { Empresa do Setor Privado nas áreas de turismo e hotelaria ou } \\
\text { saúde }\end{array}$ & 85 & 25,1 \\
\hline $\begin{array}{l}\text { Organização de Gestão Pública e/ ou Associações nas áreas de } \\
\text { turismo e hotelaria ou saúde }\end{array}$ & 16 & 4,7 \\
\hline $\begin{array}{l}\text { Representante da sociedade civil que não atua profissionalmente } \\
\text { nas áreas de turismo e hotelaria ou saúde }\end{array}$ & 169 & 50,0 \\
\hline Total & $\mathbf{3 3 8}$ & $\mathbf{1 0 0 , 0}$ \\
\hline
\end{tabular}

Fonte: Elaborado pelos autores (2020).

Dentre os respondentes, evidencia-se, conforme apresentado na Tabela 2, a predominância do gênero feminino (61,4\%), seguido de 37,1\% do gênero masculino e 1,5\% preferiram não responder. De acordo com os dados, os respondentes apresentam um perfil heterogêneo, com faixa etária bem distribuída, sendo a amostra desta pesquisa composta da seguinte forma: 28,4\% são adultos jovens entre 31 e 40 anos, $21,9 \%$ entre 51 e 60 anos e 18,9\%, entre 41 e 50 anos. 18, 9\% têm entre 21 e 30 anos e 11,2\% mais de 60 anos. Apenas 1,5\% pertencem ao grupo mais jovem, de 16 a 20 anos.

\section{Tabela 2.}

Gênero e Faixa Etária

\begin{tabular}{|l|c|}
\hline Gênero & Percentual válido (\%) \\
\hline Feminino & 61,4 \\
\hline Masculino & 37,1 \\
\hline Outros/ Não deseja informar & 1,5 \\
\hline Total & 100,0 \\
\hline Faixa etária & 1,5 \\
\hline $16-20$ & 18,0 \\
\hline $21-30$ & 28,4 \\
\hline $31-40$ & 18,9 \\
\hline $41-50$ & 21,9 \\
\hline $51-60$ & 11,2 \\
\hline Mais de 60 anos & $\mathbf{1 0 0 , 0}$ \\
\hline Total & \\
\hline Fonte: Elaborado pelos autor $(2020)$ & Pen $)$ \\
\hline
\end{tabular}

Fonte: Elaborado pelos autores (2020). 
Os dados da pesquisa apontam para uma mudança do perfil do consumidor no contexto da pandemia. Ao analisar a coluna da média da Tabela 3, que representa a média das avaliações de forma comparativa entre os períodos antes e durante a pandemia, verifica-se que todos tiveram algum tipo de alteração. Isso possibilita afirmar que todos os dados analisados apresentam algum tipo de mudança referente à comparação de períodos.

Ao observar os dados da Tabela 3 de forma mais detalhada, é também possível observar que de acordo com os respondentes (residentes na cidade do Rio de Janeiro, que não atuam no setor de turismo), a propensão a realizar viagens a lazer dentro do país após a pandemia diminuiu significativamente em média, independente da disponibilidade financeira para realizar viagens. O mesmo ocorre com o contexto da viagem internacional. Mas o fato é que, de acordo com os resultados da pesquisa, a disponibilidade financeira para realização de viagens também diminuiu com a crise sanitária.

Evidenciou-se um aumento na preocupação com a saúde para maior na qualidade de vida com a pandemia. Os residentes, respondentes da pesquisa, também afirmam que aumentou o interesse em conhecer mais o destino onde reside, no lugar de viajar para outro destino. No entanto, ao analisar o teste $\mathrm{t}$ de forma comparativa, observa-se que este foi em si o que menos apresentou mudança. Neste sentido, sugere-se que sejam feitos estudos futuros para que seja possível avaliar o motivo dos residentes não apresentarem tanto interesse em conhecer mais o próprio local onde residem. Estudos anteriores, realizados por Zouain et al (2019) apontam que existe uma carência de produtos e serviços turísticos direcionados para o residente e que o turismo da cidade do Rio de Janeiro está muito direcionado para estrangeiros, sendo caro para brasileiro. Estes podem representar alguns dos motivos, mas cabe a investigação mais aprofundada sobre esta temática. 
Tabela 3.

Teste T de Amostras Emparelhadas

\begin{tabular}{|c|c|c|c|c|c|}
\hline & & Diferenças emp & arelhadas & t & gl \\
\hline & & $\begin{array}{c}\text { Média da } \\
\text { diferença (antes } \\
\text { - durante) }\end{array}$ & $\begin{array}{l}\text { Erro } \\
\text { Padrão da } \\
\text { Média }\end{array}$ & & \\
\hline $\begin{array}{l}\text { Par } \\
1\end{array}$ & $\begin{array}{l}\text { Qual era a propensão de realizar viagem a lazer no país antes da pandemia? } \\
\text { Qual a propensão de realizar viagem a lazer no país após a pandemia? }\end{array}$ & 2,01775 &, 25670 & $7,860 * * *$ & 168 \\
\hline $\begin{array}{l}\text { Par } \\
2\end{array}$ & $\begin{array}{l}\text { Qual era a propensão de realizar viagem a lazer internacional antes da } \\
\text { pandemia? } \\
\text { - Qual é a propensão de realizar viagem a lazer internacional após a } \\
\text { pandemia? }\end{array}$ & 2,23077 & ,26408 & $8,447 * * *$ & 168 \\
\hline $\begin{array}{l}\text { Par } \\
3\end{array}$ & $\begin{array}{l}\text { O quanto considerava ter disponibilidade financeira para viajar antes da } \\
\text { pandemia? } \\
\text { - O quanto considera ter disponibilidade financeira para viajar após a } \\
\text { pandemia? }\end{array}$ & 1,20118 & ,18399 & $6,528 * * *$ & 168 \\
\hline $\begin{array}{l}\text { Par } \\
4\end{array}$ & $\begin{array}{l}\text { O quanto a saúde era uma preocupação na sua qualidade de vida antes da } \\
\text { pandemia? - O quanto a saúde se tornou uma preocupação na sua qualidade } \\
\text { de vida com a pandemia? }\end{array}$ & $-1,53571$ &, 15405 & $-9,969 * * *$ & 167 \\
\hline $\begin{array}{l}\text { Par } \\
5\end{array}$ & $\begin{array}{l}\text { Antes da pandemia, ao escolher um destino para viajar, o quanto pesquisava } \\
\text { sobre as condições sanitárias do local? - Após a pandemia, ao escolher um } \\
\text { destino para viajar, o quanto vai pesquisar sobre as condições sanitárias do } \\
\text { local? }\end{array}$ & $-3,76190$ & ,25557 & $-14,720 * * *$ & 167 \\
\hline $\begin{array}{l}\text { Par } \\
6\end{array}$ & $\begin{array}{l}\text { Antes da pandemia, o quanto considerava conhecer mais o destino onde } \\
\text { reside no lugar de viajar para outro destino? } \\
\text { - Com a pandemia, o quanto considera conhecer mais o destino onde reside } \\
\text { no lugar de viajar para outro destino? }\end{array}$ &,- 52663 & ,21284 & $-2,474 * *$ & 168 \\
\hline $\begin{array}{l}\text { Par } \\
7\end{array}$ & $\begin{array}{l}\text { O quanto se considerava um consumidor conectado (com uso de } \\
\text { internet) antes da pandemia? } \\
\text { - O quanto se considera um consumidor conectado (com uso de internet) } \\
\text { durante a pandemia? }\end{array}$ &,- 86905 &, 12252 & $-7,093 * * *$ & 167 \\
\hline $\begin{array}{l}\text { Par } \\
8\end{array}$ & $\begin{array}{l}\text { O quanto se considerava um consumidor informado antes da pandemia? } \\
\text { - O quanto se considera um consumidor informado durante a pandemia? }\end{array}$ &,- 62130 & ,11984 & $-5,184 * * *$ & 168 \\
\hline $\begin{array}{l}\text { Par } \\
9\end{array}$ & $\begin{array}{l}\text { O quanto se considerava um consumidor responsável com o meio ambiente } \\
\text { antes da pandemia? } \\
\text { - O quanto se considera um consumidor responsável com o meio } \\
\text { ambiente durante a pandemia? }\end{array}$ &,- 46429 & ,07208 & $-6,441 * * *$ & 167 \\
\hline $\begin{array}{l}\text { Par } \\
10\end{array}$ & $\begin{array}{l}\text { Antes da pandemia, o quanto se preocupava com a lotação de pessoas ao } \\
\text { visitar em um atrativo turístico? } \\
\text { - Com a pandemia, qual é o seu nível de preocupação com a lotação de } \\
\text { pessoas em um atrativo turístico? }\end{array}$ & $-4,02367$ & ,25745 & $-15,629 * * *$ & 168 \\
\hline
\end{tabular}

Nota: $* * *$ valor-p<.01; ** valor-p<.05; * valor-p<.10

Nota: $\mathrm{O}$ valor $\mathrm{p}$ está indicado na coluna de estatística t.

Fonte: Elaborado pelos autores (2020).

Ao analisar os dados de forma mais aprofundada, os resultados validam que o advento da Pandemia da Covid-19 impactou negativamente a disponibilidade financeira do viajante, conforme apresentado na Tabela 4. Observa-se uma redução percentual de $18 \%$ no consumo / 
intenção de viagens, conforme mostra a referida Tabela. Em uma escala de 0 a 10 (onde zero é "nada" e dez é "muito"), a disponibilidade financeira para viajar antes do surgimento da Covid19 era de 6,8 (Média) e durante a pandemia passou a ser 5,6 (Média). Esse dado corrobora com a atual conjuntura econômica dos consumidores brasileiros, uma vez que o desemprego, diminuição de renda e as incertezas afetam diretamente sua disponibilidade financeira não só para viagens como para a vida cotidiana.

A Carta de Conjuntura do Instituto de Pesquisa Econômica Aplicada (Instituto de Pesquisa Econômica Aplicada (IPEA, 2020) projeta queda 5\% no PIB do ano de 2020 e ressalta que "o efetivo controle da disseminação da Covid-19 é particularmente importante para o setor de serviços, que vem apresentando desempenho inferior aos demais devido às restrições ainda em vigor e ao comportamento cauteloso por parte de consumidores” (IPEA, 2020, p.1). O turismo, como parte do setor de serviços, é especialmente impactado por uma série de fatores além do financeiro, como mobilidade reduzida e mais cara, fechamento de atrativos e equipamentos essenciais à prática da atividade, questões sanitárias, entre outros.

\section{Tabela 4.}

\section{Disponibilidade Financeira Para Viajar}

\begin{tabular}{|l|r|r|r|r|r|r|}
\hline $\begin{array}{l}\text { Residentes da Cidade do Rio de } \\
\text { Janeiro }\end{array}$ & Média & N & Desvio Padrão & Erro Padrão da Média & CV & Variação \% \\
\hline $\begin{array}{l}\text { Disponibilidade financeira para } \\
\text { viajar antes da pandemia }\end{array}$ & 6,8166 & 169 & 2,38711 &, 18362 & $35 \%$ & \\
\hline $\begin{array}{l}\text { Disponibilidade financeira para } \\
\text { viajar após a pandemia }\end{array}$ & 5,6154 & 169 & 2,84730 &, 21902 & $51 \%$ & $\mathbf{- 1 8 \%}$ \\
\hline
\end{tabular}

Fonte: Elaborado pelos autores (2020).

Ao se realizar este recorte por tipo de viagem, os dados apontam que a propensão para se viajar a lazer no país, independente da disponibilidade financeira para tal atividade, também diminuiu consideravelmente, em $28 \%$ menos do que antes da Pandemia, conforme Coeficiente de Variação (CV). No contexto das viagens internacionais o quadro é ainda pior, e a propensão a viagens se reduz ainda mais, em $36 \%$ menos do que antes da Covid-19, em termos de variações percentuais, conforme apresentado na Tabela 5. 


\section{Tabela 5.}

Propensão Para Viajar, Independente da Disponibilidade Financeira

\begin{tabular}{|l|r|r|r|r|r|r|}
\hline Residentes da Cidade do Rio de Janeiro & Média & $\mathbf{N}$ & $\begin{array}{c}\text { Desvio } \\
\text { Padrão }\end{array}$ & $\begin{array}{c}\text { Erro } \\
\text { Padrão } \\
\text { da } \\
\text { Média }\end{array}$ & CV & $\begin{array}{c}\text { Variação } \\
\text { \% }\end{array}$ \\
\hline $\begin{array}{l}\text { Propensão de realizar viagem a lazer no } \\
\text { país antes da pandemia }\end{array}$ & 7,2544 & 169 & 2,77323 &, 21333 & $38 \%$ & \\
\hline $\begin{array}{l}\text { Propensão de realizar viagem a lazer no país } \\
\text { após a pandemia }\end{array}$ & 5,2367 & 169 & 3,25552 &, 25042 & $62 \%$ & $\mathbf{- 2 8 \%}$ \\
\hline $\begin{array}{l}\text { Propensão de realizar viagem a lazer } \\
\text { internacional antes da pandemia? }\end{array}$ & 6,1775 & 169 & 3,61270 &, 27790 & $58 \%$ & \\
\hline $\begin{array}{l}\text { Qual é a propensão de realizar viagem a lazer } \\
\text { internacional após a pandemia? }\end{array}$ & 3,9467 & 169 & 3,31709 &, 25516 & $84 \%$ & $\mathbf{- 3 6 \%}$ \\
\hline
\end{tabular}

Fonte: Elaborado pelos autores (2020).

Dentre os fatores citados pelos respondentes como principais limitadores para deslocamentos para fora do destino de origem, destacam-se: medo de exposição em viagem mais longa, em especial em aviões e portões de acesso (rodoviárias, aeroportos); receio e gastos ao ter de cumprir quarentena ao chegar no destino, câmbio desfavorável para viagens internacionais, tendo em vista a valorização das principais moedas utilizadas em viagens, Euro e Dólar, ao longo do segundo semestre de 2020 e ao longo do ano de 2021.

Os resultados do estudo apontam ainda que o carioca, antes de dar início à jornada da viagem, efetuará pesquisas para se informar sobre as condições sanitárias do destino que deseja visitar. Esse tipo de ação teve um aumento percentual de 79\% (Tabela 6), visto que antes da pandemia não havia uma preocupação significativa relacionada a essa questão e este não era um hábito comum entre a grande maioria dos viajantes.

De acordo com os respondentes, evidencia-se muito mais a preocupação com as condições sanitárias do destino ao realizar uma viagem. E a grande maioria afirma que antes de dar início a esta jornada irá procurar se informar mais sobre as condições da pandemia no destino a ser visitado e sobre os protocolos de segurança sanitária que os destinos estão adotando, englobando os atrativos turísticos e os meios de hospedagem.

A preocupação se estende sobre aglomeração de pessoas nos atrativos turísticos. Esse quesito era muito pouco observado antes da Covid-19, mas a pesquisa aponta que os hábitos mudaram e os viajantes cariocas estão $81 \%$ mais preocupados com o quantitativo de visitantes em um atrativo (Tabela 6), devido à atenção que estão fazendo ao distanciamento social. Esse 
tipo de ação demonstra inclusive uma responsabilidade com a própria vida e com o desenvolvimento de um turismo responsável.

Um outro aspecto interessante que foi constatado na pesquisa é sobre o respondente acreditar que a saúde se tornou uma preocupação na sua qualidade de vida com o advento da pandemia. Houve um aumento percentual de $20 \%$ nesta variável e a média subiu de 7,5 para 9,0, conforme apontam os dados na Tabela 6 a seguir.

\section{Tabela 6.}

Preocupações dos Residentes com a pandemia da Covid-19

\begin{tabular}{|c|c|c|c|c|c|c|}
\hline Residentes da Cidade do Rio de Janeiro & Média & $\mathbf{N}$ & $\begin{array}{l}\text { Desvio } \\
\text { Padrão }\end{array}$ & \begin{tabular}{|c} 
Erro \\
Padrão \\
da \\
Média \\
\end{tabular} & CV & $\underset{\%}{\text { Variação }}$ \\
\hline $\begin{array}{l}\text { O quanto a saúde era uma preocupação na sua } \\
\text { qualidade de vida antes da pandemia }\end{array}$ & 7,5417 & 168 & 2,46376 & 19008 & $33 \%$ & \\
\hline $\begin{array}{l}\text { O quanto a saúde se tornou uma preocupação } \\
\text { na sua qualidade de vida com a pandemia }\end{array}$ & 9,0774 & 168 & 1,72685 &, 13323 & $19 \%$ & $20 \%$ \\
\hline $\begin{array}{l}\text { Antes da pandemia, ao escolher um destino } \\
\text { para viajar, o quanto pesquisava sobre } \\
\text { as condições sanitárias do local }\end{array}$ & 4,7679 & 168 & 3,36408 & 25954 & $71 \%$ & \\
\hline $\begin{array}{l}\text { Após a pandemia, ao escolher um destino para } \\
\text { viajar, o quanto vai pesquisar sobre as } \\
\text { condições sanitárias do local }\end{array}$ & 8,5298 & 168 & 2,45663 & 18953 & $29 \%$ & $79 \%$ \\
\hline $\begin{array}{l}\text { Antes da pandemia, o quanto se preocupava } \\
\text { com a lotação de pessoas ao visitar em um } \\
\text { atrativo turístico }\end{array}$ & 4,9467 & 169 & 3,29368 & 25336 & $67 \%$ & \\
\hline $\begin{array}{l}\text { Com a pandemia, qual é o seu nível de } \\
\text { preocupação com a lotação de pessoas em um } \\
\text { atrativo turístico }\end{array}$ & 8,9704 & 169 & 2,08288 & ,16022 & $23 \%$ & $81 \%$ \\
\hline
\end{tabular}

Fonte: Elaborado pelos autores (2020).

Vale ressaltar que estes dados corroboram com estudo de Kock Nørfeltb, Josiassen, Assaf e Tsionas (2020), que afirmam que a situação pandêmica constitui uma mudança de paradigma nas pesquisas a respeito do comportamento do turista e tomada de decisão. Os autores explicam que o fato de a pandemia revelar e ampliar muitas das mais profundas ansiedades humanas a respeito de doenças contagiosas, danos físicos e isolamento social, traz importantes insumos para o campo de pesquisas.

Kock et al. (2020) reforçam ainda algumas observações empíricas durante a pandemia, sugerindo que a pandemia da Covid-19 reviveu as ansiedades individuais da população ao reforçar sua vulnerabilidade física e econômica. E que os conceitos psicológicos de 
etnocentrismo, xenofobia turística e aglomeração são reforçados e se relacionam à percepção de possibilidade de infecção por Covid-19.

Ou seja, para evitar o contágio e pela percepção de vulnerabilidade diante da corrente situação, alguns gatilhos psicológicos têm emergido no comportamento turístico. A turismofobia, por exemplo, que alertava o mundo sobre os conflitos sociais que o excesso de turismo poderia trazer, especialmente sobre os impactos negativos para a comunidade local e meio ambiente (Jover \& Díaz-Parra, 2020), ganha outros contornos com o advento da Covid19. A preocupação e insatisfação com a lotação de lugares turísticos é adicionada ao medo de as aglomerações trazerem ou aumentarem a infecção pelo vírus nos destinos.

Em contraponto, a preocupação com a saturação do turismo foi substituída pela apreensão com as restrições à circulação e por futuras mudanças na forma de viajar (Castello, 2020), que afeta políticas públicas e comportamentos turísticos ao redor do mundo. A incerteza, especialmente nos campos econômico e social, gera ansiedade e inquietações a respeito dos rumos do turismo, além de questionamentos sobre a forma como se darão as interações e a dinâmica global deste fenômeno.

\subsection{Relação do residente da cidade do Rio de Janeiro com o turismo e seus hábitos de consumo}

Com a intenção de entender qual a relação do carioca com a atividade turística, os resultados apontaram que em uma escala de 0 a 10, independente da disponibilidade financeira para viajar, esse respondente é amante de viagens (Média 9). Esse resultado permite inferir que ainda que haja uma mudança de perfil e hábitos de viagens, esse carioca continuará consumindo turismo, ainda que temporariamente, de forma mais recorrente no próprio Estado ou até mesmo na cidade onde reside e/ou arredores.

Este contexto de fronteiras e fluxos de viagens limitados, juntamente com o receio quanto à exposição em deslocamentos por medo de contágio, fez com que o residente começasse a olhar mais a própria cidade onde habita e arredores, incluindo a Região Metropolitana e o próprio Estado. Mas, de fato, ainda é tímido o aumento de interesse pelo próprio destino (variação percentual de $9 \%$, conforme Tabela 7) e tendo em vista que este residente não tem tanto interesse em conhecer o próprio destino (média 6,1 antes da Pandemia e 6,6, no contexto da Pandemia), observa-se uma oportunidade para se desenvolver estratégias para estimular esta mudança de cultura do público local. 
Zouain, D. M., Lohmann, P. B., Laurentis, G., Virkki, K. B., \& Bittencourt, F. T. R. (2022, jan./abr.). Os efeitos da Covid-19 no turismo da cidade do Rio de Janeiro: oportunidades e desafios.

\section{Tabela 7.}

Interesse em Conhecer Mais o Destino Onde Reside

\begin{tabular}{|l|r|r|r|r|r|r|}
\hline $\begin{array}{l}\text { Residentes da Cidade do Rio de } \\
\text { Janeiro }\end{array}$ & Média & N & Desvio Padrão & Erro Padrão da Média & CV & Variação \% \\
\hline $\begin{array}{l}\text { Antes da pandemia, o quanto } \\
\text { considerava conhecer mais o } \\
\text { destino onde reside no lugar de } \\
\text { viajar para outro destino }\end{array}$ & 6,1124 & 169 & 2,57837 &, 19834 & $42 \%$ & \\
\hline $\begin{array}{l}\text { Com a pandemia, o quanto } \\
\text { considera conhecer mais o } \\
\text { destino onde reside no lugar de } \\
\text { viajar para outro destino? }\end{array}$ & 6,6391 & 169 & 2,75052 &, 21158 & $41 \%$ & \\
\hline
\end{tabular}

Fonte: Elaborado pelos autores (2020).

Um fato observado ao analisar os dados é que o carioca, antes da pandemia, tinha a cultura e o hábito de viajar. A partir do momento que existe essa limitação para viagens, esse residente passa a ser um potencial consumidor de produtos e serviços turísticos no próprio destino. Visto que houve um pequeno aumento no interesse de conhecer mais essa cidade e a partir do momento que ele conhece mais o seu entorno, é possível que esse residente seja também responsável pela divulgação do destino.

Vale ressaltar que esse consumidor é informado, conectado em rede social e responsável com o meio ambiente. Sendo assim, verifica-se um aumento de $11 \%$ no uso da internet, assim como no quanto se considera informado (variação de $8 \%$ ) e mais informado (aumento de 6\%), de acordo com dados apontados na Tabela 8. 
Tabela 8.

Hábito de Uso da Internet e Redes Sociais

\begin{tabular}{|ll|l|r|r|r|r|r|}
\hline Residentes da Cidade do Rio de Janeiro & Média & N & $\begin{array}{l}\text { Desvio } \\
\text { Padrão }\end{array}$ & $\begin{array}{c}\text { Erro Padrão } \\
\text { da Média }\end{array}$ & CV & $\begin{array}{c}\text { Variação } \\
\text { \% }\end{array}$ \\
\hline Par7 $\begin{array}{l}\text { O quanto se considerava um } \\
\text { consumidor conectado (com uso de } \\
\text { internet) antes da pandemia? }\end{array}$ & 7,7679 & 168 & 2,02964 &, 15659 & $26 \%$ & \\
$\begin{array}{l}\text { O quanto se considera um consumidor } \\
\text { conectado (com uso de internet) } \\
\text { durante a pandemia? }\end{array}$ & 8,6369 & 168 & 1,98626 &, 15324 & $23 \%$ & $\mathbf{1 1 \%}$ \\
Par8 8 quanto se considerava um \\
$\begin{array}{l}\text { Onsumidor informado antes da } \\
\text { pandemia? }\end{array}$
\end{tabular}

Fonte: Elaborado pelos autores (2020).

Esses dados corroboram com Prahalad \& Ramaswamy (2004) que afirmam que o consumidor está mais conectado, informado e ativo, permitindo maior interação não apenas entre a demanda e a oferta, mas também consumidores entre si (C2C) e entre negócios (B2B).

Se por um lado os consumidores estão mais conectados e responsáveis com o meio ambiente, por outro, existe uma crise de saúde relacionada ao bem-estar. Um dado da World's Global Style Network (WGSN) detectou a ansiedade como tendência, como um traço cultural e geracional, assim como o medo. Os eventos atuais estão acelerando essas mudanças. O medo do consumidor - e o modo como ele responde a esse sentimento - pode levá-lo a tomar determinadas atitudes durante e após a pandemia da Covid-19. E essas questões podem ter impacto não apenas do dia a dia do residente, mas no consumo de viagens (WGSN, 2020).

Os respondentes da presente pesquisa afirmam que perceberam um aumento na carga horária de trabalho na organização onde atuam, ao longo do período da pandemia da Covid-19, conforme apresentado na Tabela 9. 


\section{Tabela 9.}

Carga Horária de Trabalho no Período de Pandemia

\begin{tabular}{|l|c|}
\hline No período da quarentena: & Percentual Válido (\%) \\
\hline A sua carga horária de trabalho na organização onde atua: \\
\hline Aumentou & 35,9 \\
\hline Manteve-se a mesma & 27,4 \\
\hline Diminuiu & 23,9 \\
\hline Não sabe responder/ Não se aplica & 12,6 \\
\hline
\end{tabular}

Fonte: Elaborado pelos autores (2020).

Ao analisar os resultados dos respondentes que atuam em empresas de turismo, percebese que o ambiente digital é uma das áreas das organizações que recebeu maior investimento ao longo da pandemia. Conforme apresentado na Tabela 10, do total de respondentes, 64,9\% afirmaram que houve aumento no investimento do ambiente digital e da interação on-line durante este período. Esse dado é corroborado pelo fenômeno da digitalização e os efeitos que têm sido percebidos na relação entre turismo e tecnologia. Segundo Silveira Medaglia, Vicentim e Barbosa (2020, p. 109), “atualmente, plataformas e ferramentas digitais estão transformando a maneira como os turistas viajam e, consequentemente, a forma como serviços turísticos são desenhados e ofertados".

Este fator pode estar diretamente relacionado à necessidade de todas as esferas, seja órgão público, privado, ou academia, a investirem em aparatos e sistemas tecnológicos para atenderem à nova realidade de trabalho e/ou contato remoto, em um momento que a interação entre os atores se faz majoritariamente pelo meio digital.

\section{Tabela 10.}

Nível de Investimento e Desenvolvimento do Ambiente Digital e Interação On-line Durante a Pandemia

\begin{tabular}{|l|c|}
\hline Durante a quarentena: & Percentual Válido (\%) \\
\hline O investimento e desenvolvimento do ambiente digital e interação on-line da sua organização: \\
\hline Aumentou & 64,9 \\
\hline Permaneceu o mesmo & 14,3 \\
\hline Diminuiu & 10,7 \\
\hline Não sabe dizer & 10,1 \\
\hline
\end{tabular}

Fonte: Elaborado pelos autores (2020). 
O fato de as organizações estarem cada vez mais em formato digital gera também oportunidade para o turismo, a partir do momento que as pessoas podem viajar a trabalho e lazer de forma conjunta. O Copenhagen Institute for Future Studies (2020) aponta como uma das tendências do setor do turismo a popularização de expressões (e práticas) como "workation", definido como trabalhar remotamente em destinos no qual normalmente o indivíduo iria para passar as férias, e "Cidades Zoom”, que evidencia a preferência por viagens para locais que proporcionem maior contato com a natureza, que possuam poucos moradores, uma restrição sanitária mais rígida do que nos grandes centros urbanos e nos quais há a possibilidade de trabalhar remotamente. Esses movimentos são alguns exemplos das mudanças de hábitos e processos que a digitalização pode provocar no turismo.

\section{Conclusões}

No contexto da pandemia da Covid-19, verifica-se que o residente na cidade do Rio de Janeiro adquire novos hábitos de viagens, confirmando que o carioca apresenta menor propensão a deslocamentos nacionais e, em especial, internacionais, após a Pandemia. Há, portanto, uma oportunidade para o carioca conhecer mais a sua própria cidade e arredores. Apesar de os dados apontarem que o residente considera conhecer mais o destino onde reside no lugar de viajar para outro destino, esse quesito ainda demonstra um aumento de forma tímida, sendo oportuno o aumento da oferta de produtos e serviços turísticos para residentes.

Vale ressaltar que a cidade do Rio de Janeiro sediou em 2016 os Jogos Olímpicos e por esse motivo sofreu uma série de transformações que devem ser aproveitadas e conhecidas por muitos cariocas: novos atrativos, áreas urbanizadas, mobilidade urbana renovada, equipamentos turísticos novos, rede hoteleira renovada e, do ponto de vista deste setor, diversificação de hotéis e diárias para os diferentes segmentos de mercado.

No entanto verifica-se a degradação e abandono em uma série de áreas da cidade e questões negativas relacionadas à violência e falta de manutenção de patrimônios que foram reformados ou construídos, sendo de alguma forma fatores restritivos para o turismo na cidade. Nesse sentido, evidencia-se que pode ser oportuno um trabalho de aproximação maior deste residente com a atividade turística na cidade, até mesmo porque ele é um importante ator a ser envolvido na recuperação e manutenção do destino.

Também foi percebido que houve aumento na preocupação dos cariocas em relação à qualidade de vida e à saúde, o que pode ser uma oportunidade para os destinos turísticos que 
desejam atrair a demanda turística do Rio de Janeiro, assim como para a própria cidade em si. Um outro ponto de atenção é com o distanciamento social e a necessidade de protocolos de segurança e comunicação das condições sanitárias dos destinos, assim como o cuidado com a mensuração da lotação dos atrativos turísticos. Todas as questões apontadas revelam medidas que possivelmente farão parte da rotina dos turistas ao longo das jornadas de viagens de agora em diante. Sendo assim, os destinos que desejam atrair esta demanda devem ficar atentos em planejar políticas e monitorar ações de forma a desenvolver um turismo mais responsável, inclusive com maior preocupação em cuidar do meio ambiente.

Dessa forma, é também importante notar que o mundo está cada vez mais digital e os residentes do Rio de Janeiro estão cada vez mais conectados, informados e responsáveis com o meio ambiente. Essa mudança de comportamento exige novas ações e melhorias para a experiência completa deste viajante, que pode, cada vez mais, inclusive, viajar para realizar trabalho e lazer em conjunto. Novas formas de turismo emergem, integrando lazer e trabalho, cuidados com a saúde e com maior atenção ao meio ambiente.

E nesse contexto, verifica-se também a necessidade dos destinos melhorarem a oferta, a abrangência e a qualidade da internet, dado que o turista - ainda que muitas vezes isolado fisicamente ou buscando distanciamento social - deseja ter a possibilidade de estar conectado e imerso no ambiente digital, usufruindo de serviços de comunicação, experiências virtuais, delivery, entre outros mais.

Entendendo as limitações em relação aos deslocamentos domésticos e em especial, internacionais, há de surgir novas alternativas para o turismo interno. Para a cidade do Rio de Janeiro verifica-se uma oportunidade para empresários, acadêmicos, gestores públicos e residentes trabalharem mais o conceito de turista cidadão no destino, sendo possível um ganho para ativação do turismo na cidade. Do ponto de vista mercadológico, tanto de empresários, gestores públicos e privados que trabalham fazendo o marketing e a divulgação do destino, há a possibilidade de olhar para esse potencial consumidor, o residente, a fim de propor novas significações para o turismo no destino e seus habitantes.

O presente artigo aponta ainda a necessidade de investimento em informação e educação e sensibilização da população residente e dos visitantes em prol do desenvolvimento de um turismo responsável e de um olhar mais cuidadoso com o território. Evidencia-se a necessidade de um trabalho de sensibilização contínua e de realizar pesquisas de avaliação e de observação em parceria com o setor privado, as instituições de ensino superior de turismo e o setor público. 
A comunidade local deve estar informada e preparada para continuar a acolher da melhor forma os visitantes que chegarão após a retomada da atividade turística, mas também para usufruir de sua cidade de forma segura. Isso implica que os gestores do destino devem prestar atenção em como lidar com possíveis reações adversas resultantes de eventuais aglomerações ou recebimento de turistas provenientes de locais mais gravemente afetados pela pandemia, priorizando o desenvolvimento de um turismo cada vez mais responsável.

Tendo em vista este debate, a presente pesquisa traz contribuições para 0 desenvolvimento de estudos teóricos a partir de embasamento empírico. Em relação ao campo de estudos sobre o Turismo nas Ciência Humanas e Sociais, gera discussões importantes sobre o protagonismo dos residentes no processo e na dinâmica turística de um destino. E, por fim, ao considerar o contexto atual da pandemia da Covid-19, os dados levantados podem ter importantes rebatimentos para a produção acadêmica ainda incipiente sobre o tema, especialmente ao se considerar o lócus da pesquisa, ou seja, a cidade do Rio de Janeiro. Ademais, a abordagem teórica e metodológica apresentada pode ser particularmente interessante para apoiar as políticas públicas de turismo na cidade do Rio de Janeiro, bem como pode contribuir para equacionar alguns dos principais desafios para o turismo na cidade futuramente.

Sugere-se que sejam feitos futuros estudos tendo esta referência de tempo do ano de 2020 como um marco temporal, para que seja possível uma análise comparativa com série histórica. Também se recomenda-se que sejam coletados dados em outros municípios do Rio de Janeiro, estados do Brasil e países, com amostra que possibilite comparação entre as diferentes realidades. E ainda, que pesquisas futuras investiguem como as novas formas de fazer turismo irão afetar as relações entre turistas e residentes.

\section{Referências}

Abdala, V. (2020). Congresso Mundial de Arquitetos é adiado para 2021. Agência Brasil. Recuperado em 02 julho, 2021, de https://agenciabrasil.ebc.com.br/geral/noticia/202003/congresso-mundial-de-arquitetos-e-adiado-para-2021

ALG Transport \& Infrastructure. (2020). Impact of coronavirus on the global supply chains. Recuperado em 20 outubro, 2020, de https://algnewsletter.com/logistics/impact-ofcoronavirus-on-the-global-supply-chains/.

Angus, A. (2018) Top 10 global trends for 2018 emerging forces shaping consumer behaviors. London: Eutomonitor International. 
Ayittey, F. K., Ayittey, M. K., Chiwero, N. B., Kamasah, J. S., \& Dzuvor, C. (2020) Economic impacts of Wuhan 2019-nCoV on China and the world. Journal of Medical Virology, 92(5), 473-475. Doi: https://doi.org/10.1002/jmv.25706.

Bartholo, R., Sansolo, D. G., \& Bursztyn, I. (2009). Turismo de base comunitária: diversidade de olhares e experiências brasileiras. Rio de Janeiro: Letra e Imagem.

Bartholomeu, M. C., Tunes, R., \& Lencioni, S. (2020). Megarregião Rio de Janeiro-São Paulo e o surto de COVID-19: desigualdades espaciais no contexto da globalização. $E$ metropolis. (42), 6-20. Recuperado em 01 dezembro, 2021, de http://emetropolis.net/edicao/n42

Björk, P. (2014). The DNA of tourism service innovation. A Quadruple Helix Approach, 181202. Doi: https://doi.org/10.1007/s13132-014-0183-x

Bolfarine, H., \& Bussab, W. O. (2005). Elementos de amostragem. São Paulo: Edgard Blucher.

Castello, V. (Junio/2020). Desafíos y oportunidades para el turismo en el marco de la pandemia COVID-19. Cuadernos de Política Exterior Argentina (Nueva Época), 131, 115-118. Doi: https://doi.org/10.35305/cc.vi131.85

CNN Brasil. (2021). Japão diz que cabe ao COI decidir se Olimpíada de Tóquio vai acontecer. Recuperado em 02 julho, 2021, de https://www.cnnbrasil.com.br/esporte/japao-diz-que-cabe-ao-coi-decidir-se-olimpiadade-toquio-vai-acontecer/.

Coelho, H. (2020). Hotéis Fasano, Windsor, Sheraton e rede Ibis anunciam fechamento durante a pandemia da Covid-19. G1. Recuperado em 21 maio, 2020, de https://g1.globo.com/rj/rio-de-janeiro/noticia/2020/04/02/hoteis-fasano-windsorsheraton-e-rede-ibis-anunciam-fechamento-durante-a-pandemia-da-covid-19.ghtml.

Comunidade Sebrae (2020). Seu negócio está na low touch economy? [Blog]. Recuperado em 20 outubro, 2020, de https://comunidadesebrae.com.br/blog/seu-negocio-esta-na-lowtouch-economy.

Cooke, P., \& Nunes, S. L. (2020). Post-Coronavirus regional innovation policies: from mega to giga and beyond through sustainable spatial planning of global tourism. European Planning Studies. Doi: https://doi.org/10.1080/09654313.2021.1936463

Couper, M. P. (2005). Technology trends in survey data collection. Social Science Computer, 23(4), 486-501. Doi: https://doi.org/10.1177/0894439305278972

Copenhagen Institute for Future Studies (2020). Pílula do Amanhã - Turismo: o nosso desejo inato de viajar não desapareceu. Recuperado em 20 julho, 2021, de https://cifs.dk/publications/digest/

Everingham, P., \& Chassagne, N. (2020). Post COVID-19 ecological and social reset: moving away from capitalist growth models towards tourism as Buen Vivir. Tourism Geographies, 22(3), 555-566. Doi: https://doi.org/10.1080/14616688.2020.1762119 
Euromonitor International. (2020). 10 Tendências globais de consumo 2020: como mapear consumidores e construir uma estratégia de negócios competitiva. Recuperado em 20 outubro, 2020, de https://go.euromonitor.com/white-paper-EC-2020-Top-10-GlobalConsumer-Trends-PG.html.

Findlater, A., \& Bogoch, I. I. (2018). Human mobility and the global spread of infectious diseases: a focus on air travel. Trends in Parasitology, 34(9), 772-783.

G1. (2021). Olimpíada de Tóquio: Japão proíbe a entrada de turistas estrangeiros.

Recuperado em 02 julho, 2021, de

https://g1.globo.com/mundo/noticia/2021/03/20/olimpiada-de-toquio-japao-proibe-aentrada-de-turistas-estrangeiros.ghtml.

Gastal, S. (2006). Turista cidadão: uma contribuição ao estudo da cidadania no Brasil. Anais do Congresso Brasileiro de Ciências da Comunicação, Brasília, DF, Brasil, 19.

Gastal, S., \& Moesch, M. (2007). Turismo, políticas públicas e cidadania. São Paulo: Aleph.

Gössling, S., Scott, D., Hall, M. (2020). Pandemics, tourism and global change: a rapid assessment of COVID-19. Journal of Sustainable Tourism Doi: https://doi.org/10.1080/09669582.2020.1758708

Instituto de Pesquisas Econômicas Aplicadas. (2020). Visão Geral da Conjuntura. Carta de Conjuntura. n. 48, $3^{\circ}$ trimestre 2020. Brasil: IPEA. Recuperado em 15 outubro, 2020, de

https://www.ipea.gov.br/portal/images/stories/PDFs/conjuntura/201001_cc_48_visao_ geral.pdf.

Irving, M. A. (2009). Reinventando a reflexão sobre turismo de base comunitária: inovar é possível? In R. Bartholo, D. G. Sansolo \& Bursztyn, I. (Orgs.). Turismo de base comunitária: diversidade de olhares e experiências brasileiras (pp. 108-119). Rio de Janeiro: Letra e Imagem.

James, A., Ravichandran, S., Chuang, N-K., \& Bolden, E. (2017). Using lifestyle analysis to develop lodging packages for staycation travelers: an exploratory study. Journal of Quality Assurance in Hospitality \& Tourism, 18(4), 387-415. Doi: https://doi.org/10.1080/1528008X.2016.1250240

Jansen, K. J., Corley, K. G., \& Jansen, B. J. (2007). E-Survey Methodology. In R. A. Reynolds, R. Woods \& J. D. Baker (2007), Handbook of research on electronic surveys and measurements (p. 384). [S.L.]: Idea Group Inc (Igi).

Jesus, D. S. V., Kamlot, D., Dubeu, V. J. C (2020). Innovation in the new normal interactions, the urban space, and the low touch economy: the case of Rio de Janeiro in the context of the Covid-19 pandemic. International Journal of Social Science Studies, 8(5), 1727. Recuperado em 01 dezembro, 2021, de https://ideas.repec.org/a/rfa/journl/v8y2020i5p17-27.html 
Johns Hopkins University Medicine. (2020). COVID-19 Dashboard by the Center for Systems Science and Engineering. Recuperado em 13 novembro, 2020, de https://coronavirus.jhu.edu/map.html

Jover, J, Díaz-Parra, I (2020) Gentrification, transnational gentrification and touristification in Seville, Spain. Urban Studies, 57(15), 3044-3059. Doi: https://doi.org/10.1177/0042098019857585

Kock, F., Nørfeltb, A., Josiassen, A., Assaf, A.G., \& Tsionas, M.G. (2020). Understanding the COVID-19 tourist psyche: the evolutionary tourism paradigm. Annals of Tourism Research, 85.

Kraenzlin , S., Meyer, C., \& Nellen, T. (2020). COVID-19 and regional shifts in Swiss retail payments. Swiss Journal Economics and Statistics, 156, 14. Doi: https://doi.org/10.1186/s41937-020-00061-x

Lehto, X., Davari, D., \& Park, S. (2020). Transforming the guest-host relationship: a convivial tourism approach. International Journal of Tourism Cities, 6(4), 1069-1088. Doi: https://doi.org/10.1108/IJTC-06-2020-0121

Maciel, T. M. F. B., \& Alves, M. B. (2015). A importância da Psicologia Social Comunitária para o Desenvolvimento Sustentável. Pesquisas e Práticas Psicossociais, 10(2), 272282. Recuperado em 01 de dezembro de 2021, de http://pepsic.bvsalud.org/scielo.php?script=sci_arttext\&pid=S1809$89082015000200005 \& \operatorname{lng}=\mathrm{pt} \& \operatorname{lng}=\mathrm{pt}$

Mantecón, A. (2020). La crisis sistémica del turismo: una perspectiva global en tiempos de pandemia. In M. S. C., R. H. Martín, \& N. P. Fumero (Orgs.). Turismo pos-COVID-19 Reflexiones, retos y oportunidades (pp. 19-30). La Laguna, España: Cátedra de Turismo CajaCanarias-Ashotel de la Universidad de La Laguna. Recuperado em 17 outubro, 2020, de https://dialnet.unirioja.es/servlet/libro?codigo=770475.

Martín, R. H. (2020). Un enfoque sistémico para entender y afrontar la crisis turística. In M. S. C., R. H. Martín, \& N. P. Fumero (Orgs.). Turismo pos-COVID-19 Reflexiones, retos y oportunidades (pp. 45-50). La Laguna, España: Cátedra de Turismo CajaCanarias-Ashotel de la Universidad de La Laguna. Recuperado em 17 outubro, 2020, de https://dialnet.unirioja.es/servlet/libro?codigo=770475.

Organização para a Cooperação e Desenvolvimento Econômico. (2005). Glossary of Statistic Terms. Statistics Portal. Recuperado em 20 outubro, 2020, de https://stats.oecd.org/glossary/detail.asp?ID=2620.

Prahalad, C. K., \& Ramaswamy, V. (2004). Co-creating unique value with customers. Strategy \& Leadership, 32(3), 4-9. Doi: https://doi.org/10.1108/10878570410699249

Rabinovici, A., \& Irving, M. A. (2015). Participação social e turismo: uma perspectiva crítica sobre os projetos desenvolvidos por ONGs em áreas protegidas. In M. Irving, C. G. O. Rodrigues, A. Rabinovici, \& H. A. Costa (Orgs). Turismo, áreas protegidas e inclusão 
social: Diálogos sobre saberes e fazeres (pp.143-175). Rio de Janeiro: Folio Imagem; Letra e Imagem.

Sánchez, A. V. (2020). Estrategias de destinos y empresas en el mercado turístico posCOVID-19. In M. S. C., R. H. Martín, \& N. P. Fumero (orgs.). Turismo pos-COVID19 Reflexiones, retos y oportunidades (pp. 147-160). La Laguna, España: Cátedra de Turismo CajaCanarias-Ashotel de la Universidad de La Laguna. Recuperado em 17 outubro, 2020, de https://dialnet.unirioja.es/servlet/libro?codigo=770475.

Serviço Brasileiro de Apoio às Micro e Pequenas Empresas (2020). Boletim de Tendências Ano 2020. Inteligência Setorial. Recuperado em 20 outubro, 2020, de https://www.sebrae.com.br/sites/PortalSebrae/sebraeaz/boletins-de-impacto-etendencias-setoriais,2e1cb5241c951710VgnVCM1000004c00210aRCRD.

Silveira, C.E., Medaglia, J., Vicentim, J. M., \& Barbosa, D. P. (2020). Transformações na sociedade e no mercado de trabalho: a inserção do profissional de turismo no cenário pós-pandemia do Covid-19. Revista Acadêmica Observatório de Inovação do Turismo, XVI(Especial) 106-130. Doi: https://doi.org/10.17648/raoit.v14n4.6679

Tsai, M. C. (março/2021). Developing a sustainability strategy for Taiwan's tourism industry after the COVID-19 pandemic. Plos One, 16(3), e0248319. Doi: https://doi.org/10.1371/journal.pone.0248319

Tunes, R. (2016). Geografia da inovação: o debate contemporâneo sobre a relação entre território e inovação, Espaço e Economia [Online], 9. Doi: https://doi.org/10.4000/espacoeconomia.2410

Valencio, N., \& De Oliveira, C. M. (2020). COVID-19 crises entremeadas no contexto de pandemia (antecedentes, cenários e recomendações). São Carlos: UFSCar/CPOI

Watt, J. (1997). Usando a Internet para pesquisas quantitativas. Quirk's Marketing Research Review, 248, 1-5. Recuperado em 8 março, 2020, de https://www.quirks.com/articles/using-the-internet-for-quantitative-survey-research.

WGSN (2020). Estratégias e tendências de consumo. Coronavírus: aceleradores globais de mudança. Recuperado em 17 outubro, 2020, de https://www.wgsn.com/content/board_viewer/\#/86743/pt/page/1.

Zouain, D. M., Lohman, P. B., Virkki, K. B., Cardoso, G. De L. (setembro/2019). Inovações no destino e o papel de cocriação do residente: um estudo após os Jogos Olímpicos no Rio de Janeiro. Anais do XVI Seminário da Associação Nacional de Pesquisa e PósGraduação em Turismo, Curitiba/PR, 16. 